\title{
STUDY ON TMD, SHEAR WALLED STRUCTURE FOR REDUCING EARTHQUAKE INDUCED BUILDING MOTION
}

\author{
Deepthi Ramesh ${ }^{1}$, Sandeep Kumar D.S ${ }^{2}$, Chethan Kumar B ${ }^{3}$ \\ ${ }^{1}$ Post Graduate Student, CADD Structure, PESCE, Mandya, India \\ ${ }^{2}$ Assistant Professor, CADD Structure, PESCE, Mandya, India \\ ${ }^{3}$ Assistant Professor, Structural Engineering, VVIT, Bangalore, India
}

\begin{abstract}
In present day structure as well as literature often contains and deals with the undesirable forces caused due to severe earthquake or even by wind, which may cause unpleasant motion which straight away leads to catrascopic failure of the structure in different modes of failure, it's essential that vibration analysis to be carried out with necessary modification to eliminate vibration or at least to reduce it as much as possible, the seismic reposes can be attenuated by reducing either the excitation or the response of structure to the excitation, so in present paper an finite element software used for the computational technique to obtain approximate solution by representing physical domain problem with finite element my means of meshing which gives insight details \& proposal related to seismic control device with other lateral load resisting system such as shear wall by accounting the effect of masonry infill which has been usually neglected during conventional design practice to protect high rise structural system from earthquake damage.
\end{abstract}

Keywords: Optimal tune mass damper, Seismic retrofit, Energy dissipation device etc... ****

\section{INTRODUCTION}

Current day practice in severe earthquake prone zones uses several modern retrofitting techniques to strengthen the existing structure, in which most popular is conventional approach (Column jacketing, adding steel bracing, adding new shear wall, etc..), By base isolation technique (Friction Pendulum bearing ,HRD, LRD), By passive energy dissipation device control device (TMD).

It's a most challenging task that to retrofit existing building where structural engineer face lot of problem in order to maintain heritage \& architectural value of the structure, which increases the complexity in retrofitting work, since there no particular cookbook available. With several people's effort, now we are able to do very fast linear and nonlinear analysis by the foundation laid down great scholars namely Galerkin, Rayleigh, Bathe, Clough and Ritz. There are several step involved in finite element modeling such as preprocessing, post processing \& structural engineer should possess sound knowledge related to these steps in modeling stage otherwise. It will be just "garbage in" "garbage out" to the finite element tool which we are using in present day.

\subsection{Seismic Damper}

Damper can place in structure similar to bracing and acts as a hydraulic shock absorber in vehicles

Types of Damper:

1) Viscous Damper

2) Friction Damper

3) Yielding Damper
Viscous Damper: This one of the passive control devices, which adds supplementary damping to the structure, to reduce part of lateral load induced, consisting pipe and piston filled with viscous fluid\& this arrangement will be placed diagonally like a bracing in between two adjacent columns.

Friction Damper: Friction damper has developed by pall and marsh in 1982 which resembles like X bracing in frame, It consist of steel plates specially treated and clamped together with high strength bolts to develop breaking style friction that sow down the motion of vibrating building and dissipate energy. Further this friction damper checked for slippage under lateral loads, again friction damper is slightly modified with copper pads impregnated with graphite in steel casing.

\subsection{Diagonal Strut Width}

The effect of infill in structure is accounted in the present study by stimulating infill wall as diagonal strut . Thickness of strut will be equal to thickness of wall, where as in case of width, we adopted well know formula given by Stafford smith (1966). Following parameters are essential in calculation of width those are Elastic modulus of the infill \& concrete, moment of inertia of frame, length of infill panel, and height of infill panel.

\subsection{Objective}

$>$ To check feasibility of controlled structure with respect to TMD \& shear wall structure.

$>$ To study effect of infill in the structure. 
> To study the effect of structural responses such as lateral displacement, story drift, story shear, overturning moment.

\section{BUILDING DESCRIPTION}

\section{Structure}

Story height

No Story

Beam

Column

Slab

Grade of concrete: M25

Grade of steel : Fe 415

Soil type : : Soft, Medium, Hard

Seismic Zones : II, III, IV, V

\section{MODELING AND ANALYSIS}

Following models are used in the present study, in the below figures \& TMD structure is modeled using link element in roof top level.

Model 1: Controlled structure

Model 2: Corner shear wall structure

Model 3: Peripheral shear wall structure

Model 4: Diagonal strut in filed structure

Model 5: Tuned mass damper structure

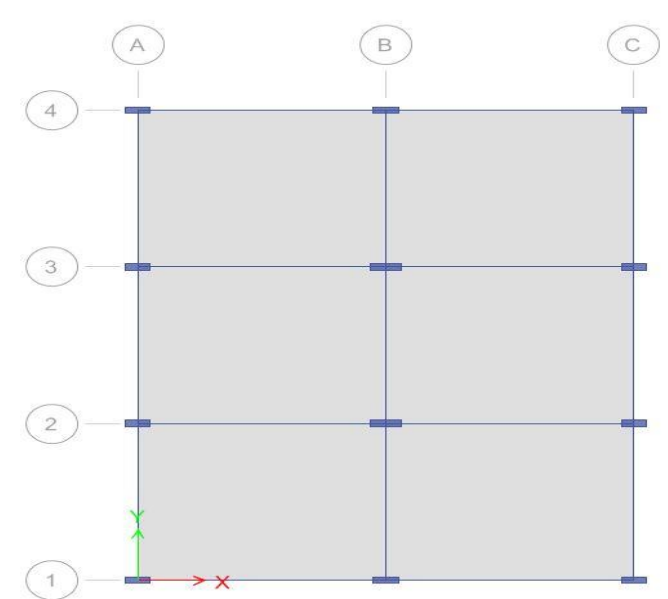

Fig 1: Plan of Controlled Structure.

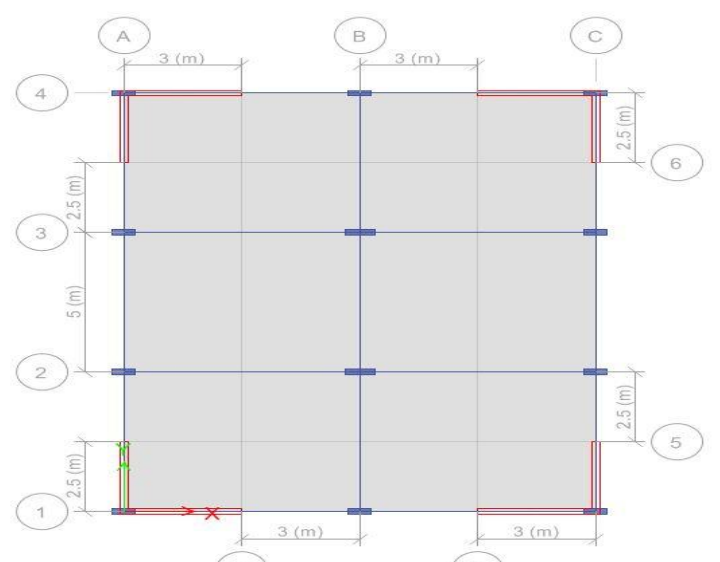

Fig 2: Plan of Corner Shear Wall Structure.

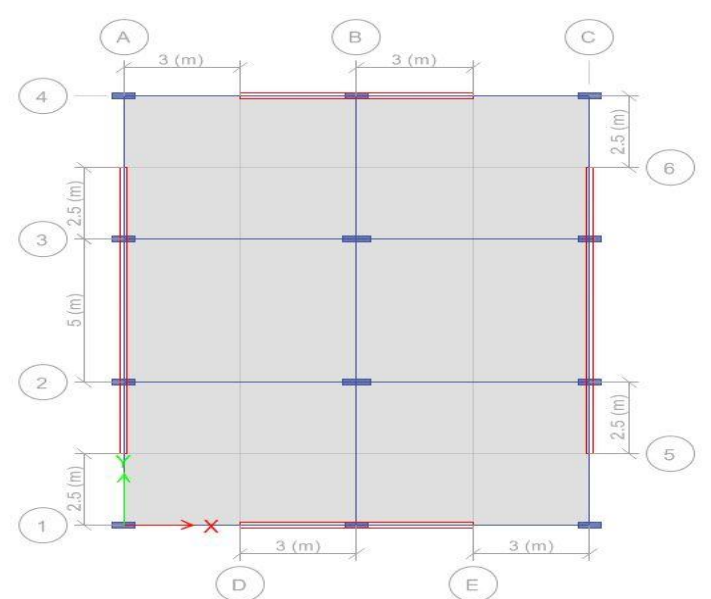

Fig 3: Plan of Peripheral Shear Wall Structure.

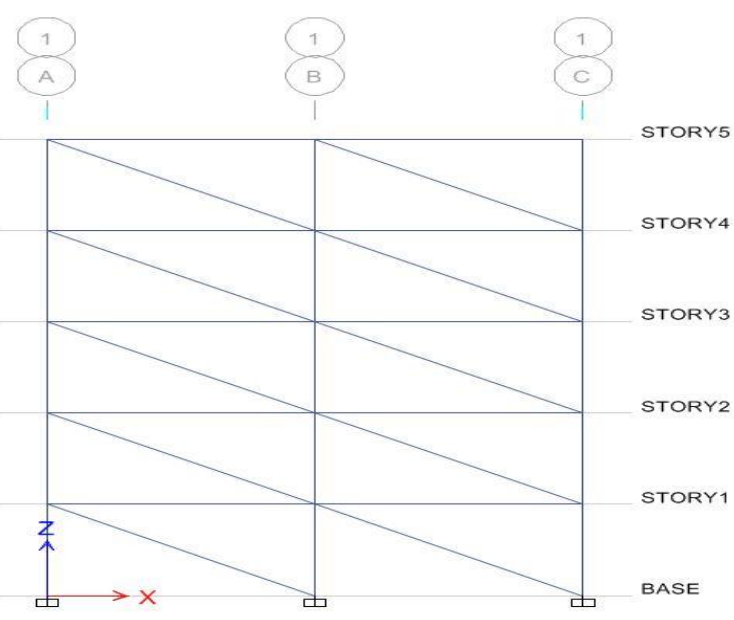

Fig 4: Elevation View of Diagonal Strut Model.

\section{RESULTS}

\subsection{Lateral Displacement}

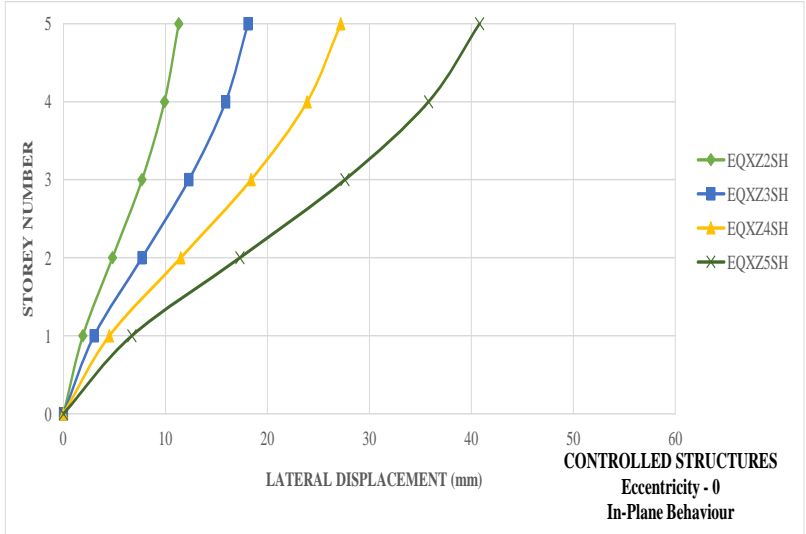

Fig 5: Lateral displacement of Controlled Structure in Hard Soil Condition.

Legend:

CS : Controlled Structure

CSW : Corner Shear Wall

TMD : Tuned Mass Damper

PSW : Peripheral Shear Wall

DS : Diagonal Strut 


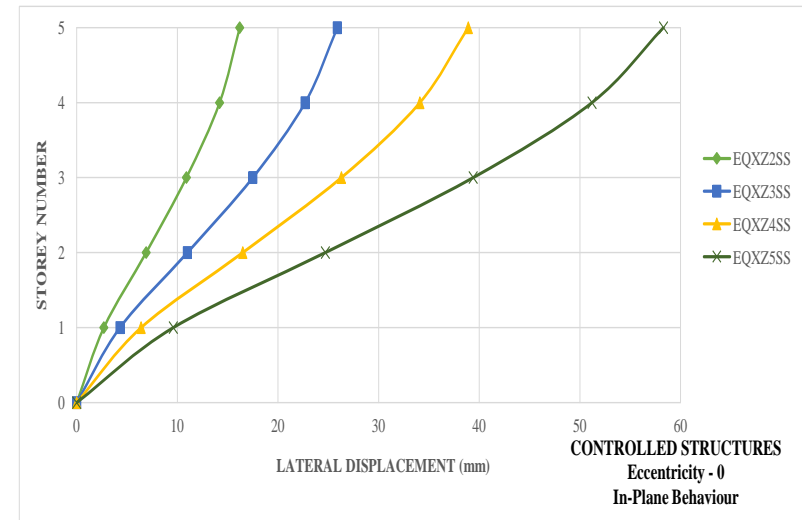

Fig 6: Lateral Displacement (mm) of Controlled Structure in Soft Soil Condition.

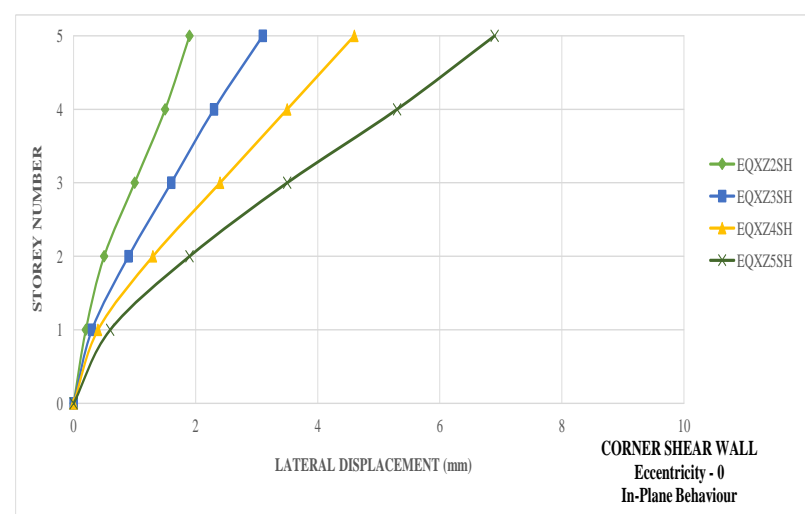

Fig 7: Lateral Displacement (mm) of Corner Shear Wall Structure in Hard Soil Condition.

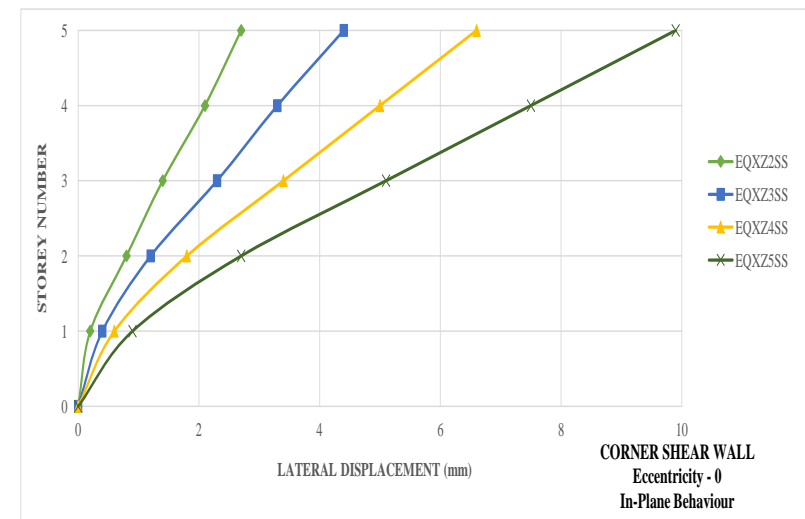

Fig 8: Lateral Displacement (mm) of Corner Shear Wall Structure in Soft Soil Condition.

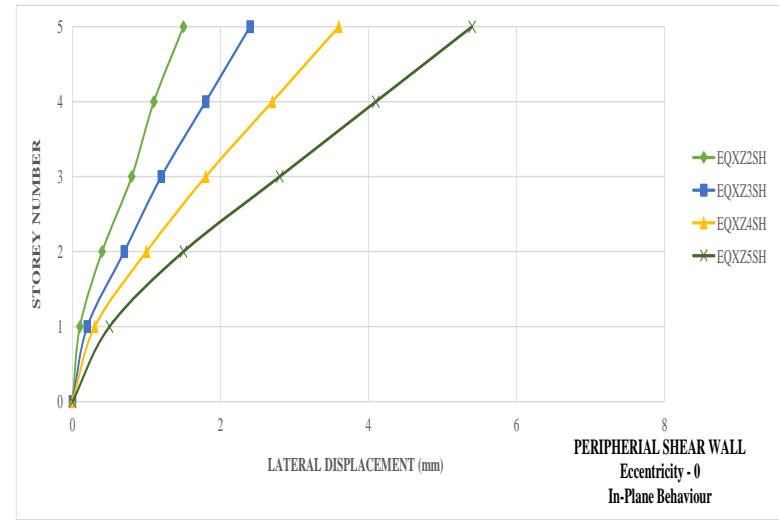

Fig 9: Lateral Displacement (mm) of Peripheral Shear Wall Structure in Hard Soil Condition.

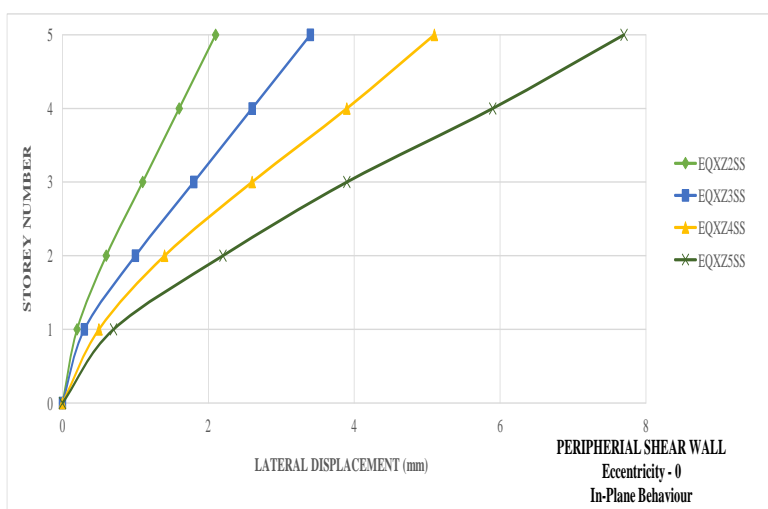

Fig 10: Lateral Displacement (mm) of Peripheral Shear Wall Structure in Soft Soil Condition.

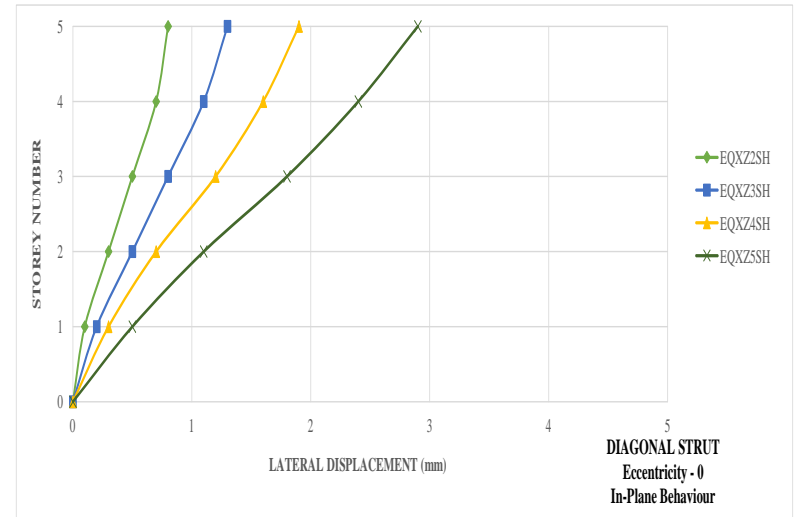

Fig 11: Lateral Displacement (mm) of Infill Wall Structure in Hard Soil Condition. 


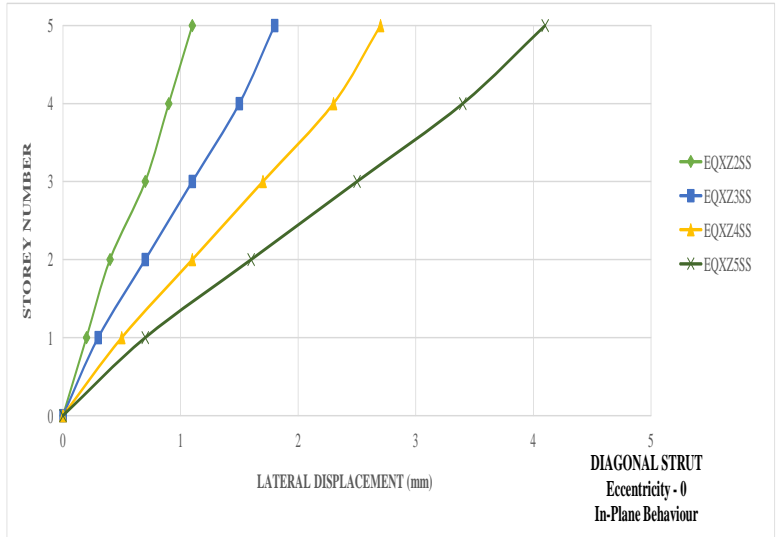

Fig 12: Lateral Displacement (mm) of Infill Wall Structure in Soft Soil Condition.

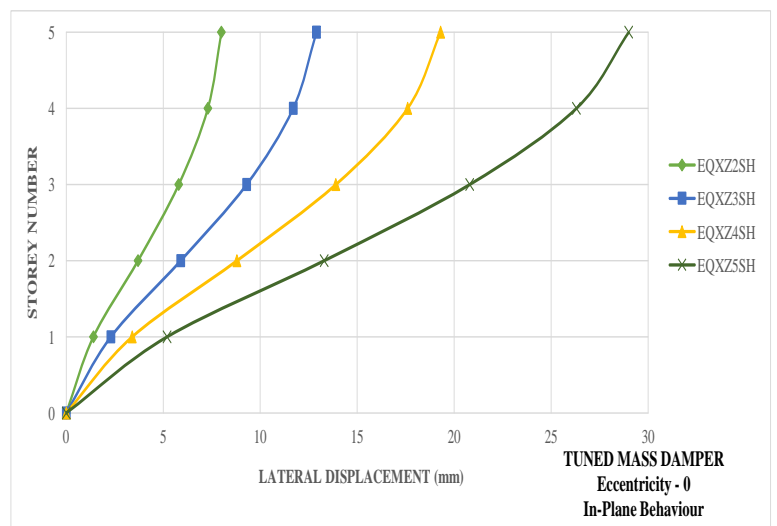

Fig 13: Lateral Displacement (mm) of TMD Structure in Hard Soil Condition.

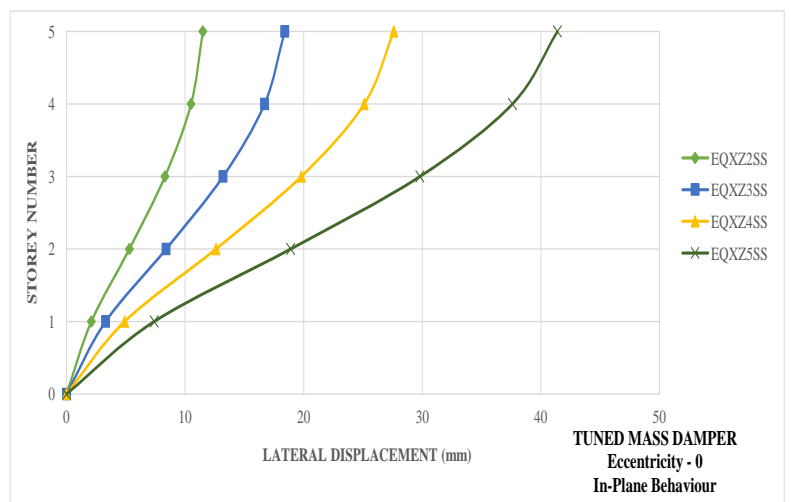

Fig 14: Lateral Displacement (mm) of TMD Structure in Soft Soil Condition.

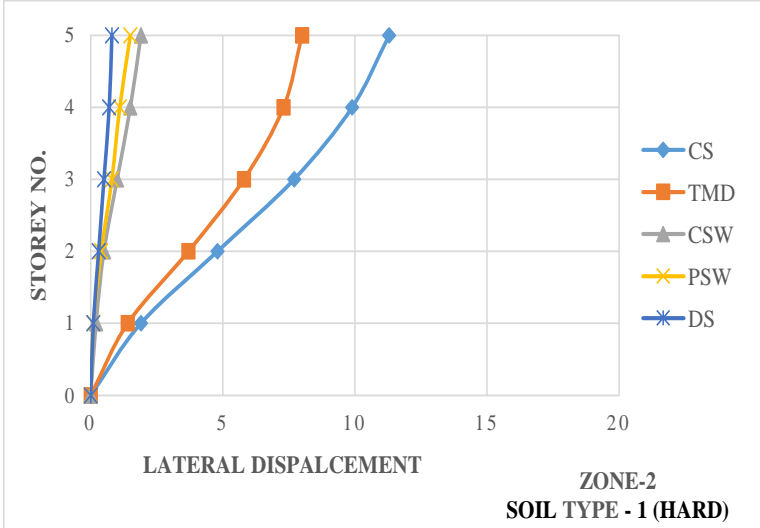

Fig 15: Comparison of Lateral Displacement ( $\mathrm{mm})$ in Zone 2 Hard Soil Condition.

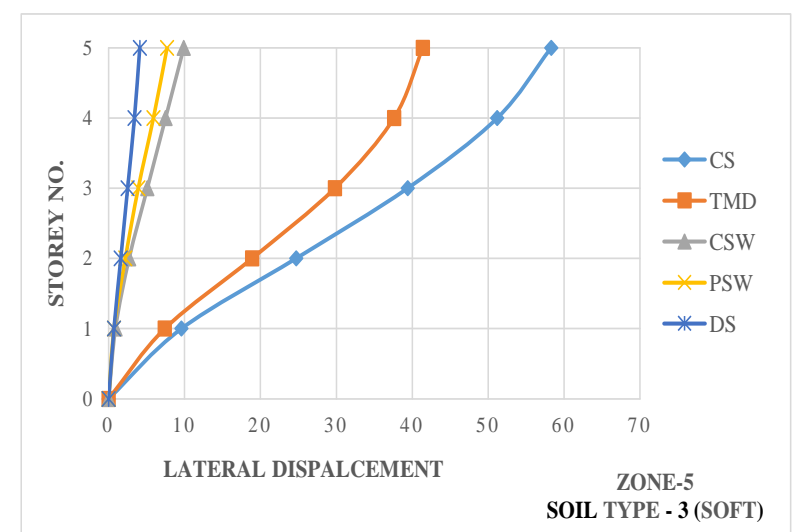

Fig 16: Comparison of Lateral Displacement ( $\mathrm{mm})$ in Zone 5 Soft Soil Condition.

\subsection{Story Drift:}

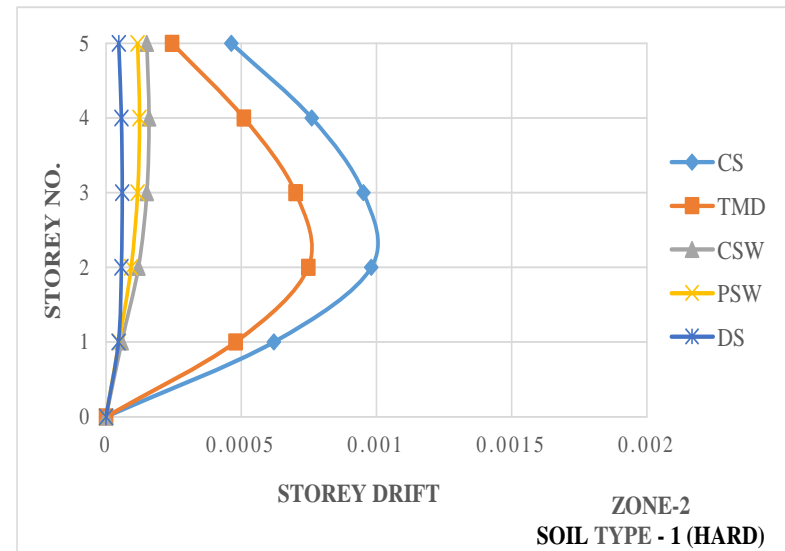

Fig 17: Comparison of Story Drift of in Zone 2 Hard Soil Condition. 


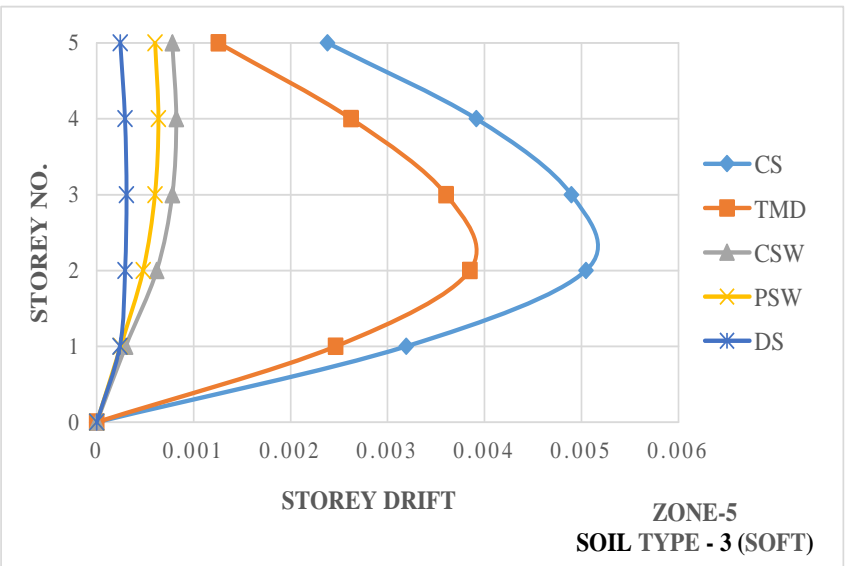

Fig 18: Comparison of Story Drift of in Zone 5 Soft Soil Condition.

\subsection{Story Shear}

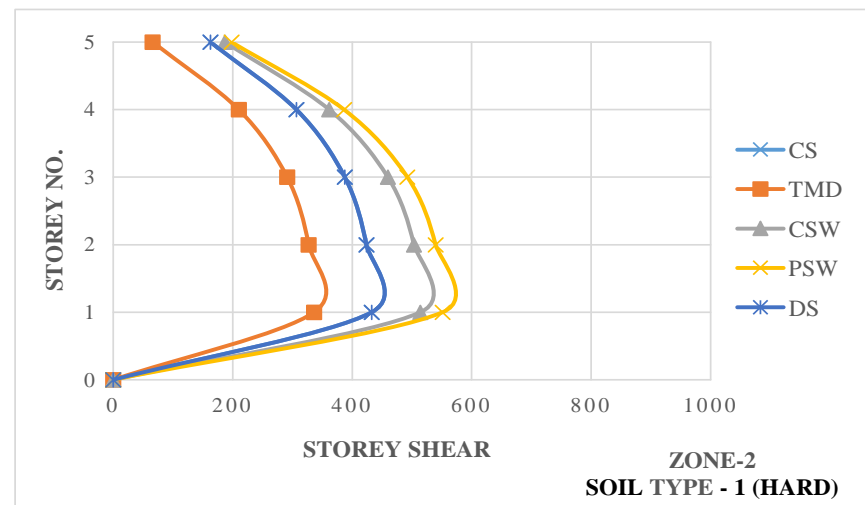

Fig 19: Comparison of Story Shear $(\mathrm{kN})$ in Zone 2 Hard Soil Condition.

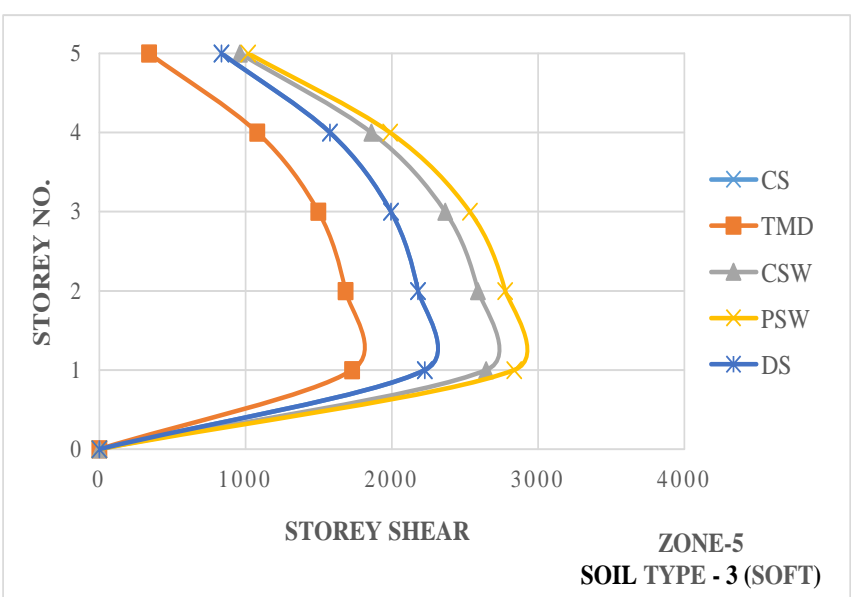

Fig 20: Comparison of Story Shear $(\mathrm{kN})$ in Zone 5 Soft Soil Condition.

\section{CONCLUSION}

Innovative strategies driven towards improving the structural response, so study reported in the present paper is concerned with reduction of seismic response using tuned mass damper, shear wall structure by accounting effect of infill underseismic loading based on IS 1893-2002 as a main emphasis.
1. It is clearly visible from above graph that propped TMD is quite effective in all seismic prone zones in critical soft soil condition and dual combination of will be more effective to resist lateral loads\&also its quite economical in cost with compare to shear walled structure. Hence, seismic protection has been validated by excellent performance of building fitted with TMD.

2. It can be expected that TMD application approach will be applied to renovation \& retrofitting work, Since past research clearly illustrates that addition of extra stiffness to the structure will result in decrease in the model time period\& other seismic response, even it stands true in the present study with the introduction of shear wall\& TMD.

3. The response of large lateral displacement encountered by flexural structure can be mitigated if we consider infill effect. The account of infill reduces the lateral displacement, story drift values compared to bare Frame structure \& its follows in the order of bare frame, TMD without infill frame, infill frame structure, and TMD structure with infill, shear wall structure.

4. From equivalent static analysis it can be concluded that, the type of soil and zone in which structure is located influences story shear values, for soft soil zone 5 will be more compared to hard soil zone 2.with introduction of shear wall story shear and base shear value will be increases since seismic weight is directly proportional to dead weight of structure, whereas with the introduction of TMD story shear value decreased drastically.

\section{REFERENCES}

[1] Higgins Christopher, Chen Sheng-Jin,Chou Fang, "Testing and Analysis of a Steel Frame with Viscoelastic Dampers" $11^{\text {th }}$ World Conference on Earthquake Engineering, Paper ID -1961, Pp no 1-8, Mexico, 1996

[2] Kato Asao, Seki Mastutaro, Shirahama Kenji, En Kosiro, "Seismic Safety Evaluation of Steel Damper for Base Isolation" $11^{\text {th }}$ World Conference on Earthquake Engineering, Paper ID -803, Pp no 1-8, Mexico, 1996

[3] Hashizume Hisayoshi, Nagataki Yoshiaki, Takaki Masayoshi, HiramatsuTomotaka, Okazaki Takao,Kasai Shouichi, "Building Vibration Isolation System with Spring and Viscoelastic Damper" $11^{\text {th }}$ World Conference on Earthquake Engineering, Paper ID -1445, Pp no 1-8, Mexico, 1996

[4] Blekhertnan Alexander N, "Mitigation of Response of High-Rise Structural Systems by Means of Optimal Tuned Mass Dampers" $11^{\text {th }}$ World Conference on Earthquake Engineering, Paper ID -89, Pp no 1-6, Mexico, 1996

[5] Chen Genda, "Multi-Stage Tuned Mass Damper" $11^{\text {th }}$ World Conference on Earthquake Engineering, Paper ID -1326, Pp no 1-8, Mexico, 1996

[6] Dampers Denial Dionisio, "Influence of Ground Motion Characteristics on the Effectiveness of Tuned 
Mass" $11^{\text {th }}$ World Conference on Earthquake Engineering, Paper ID -1455, Pp no 1-8, Mexico, 1996

[7] Hayes Jr. John R., Foutch Douglas A, Brady Pamalee $\mathrm{A}$, "Experimental Investigation of the Use of Viscoelastic Dampers to Rehabilitate a Reinforced Concrete Flat Slab Structure" $11^{\text {th }}$ World Conference on Earthquake Engineering, Paper ID -420, Pp no 18, Mexico, 1996

[8] Chang H.S.E, Jeing J.C, “Three-Dimensional Analysis of Viscous Damper System for Seismic Retrofit of Building" $11^{\text {th }}$ World Conference on Earthquake Engineering, Paper ID -94, Pp no 1-8, Mexico, 1996

[9] Fu Yaomin, “ Frame Retrofit by Using Viscous and Viscoelastic Dampers" $11^{\text {th }}$ World Conference on Earthquake Engineering, Paper ID -428, Pp no 1-8, Mexico, 1996

[10] Maison Bruce F, "VE Dampers for Upgrade of Northridge Damaged Steel Building" $11^{\text {th }}$ World Conference on Earthquake Engineering, Paper ID 1437, Pp no 1-8, Mexico, 1996

[11] Rao Rajesh, Gergely Peter, White Richard N, "A Simplified Design Method for Retrofit of Gravity Load Design RC Frames with Friction Dampers" $11^{\text {th }}$ World Conference on Earthquake Engineering, Paper ID -1691, Pp no 1-8, Mexico, 1996

[12] Gavin Henri P, Hanson Robert D. Mcclamroch N. Harris, "Control of Structures Using Electrorheological Dampers" $11^{\text {th }}$ World Conference on Earthquake Engineering, Paper ID -272, Pp no 18, Mexico, 1996

[13] Hirai J, Naruse M. Abiru H, "Structural Control with Variable Friction Damper for Seismic Response" $11^{\text {th }}$ World Conference on Earthquake Engineering, Paper ID -1934, Pp no 1-8, Mexico, 1996

[14] Datta T. K, Singh S, Gupta P, "Performance of Tuned Active Mass Damper in Controlling Seismic Response of Building Frames" $11^{\text {th }}$ World Conference on Earthquake Engineering, Paper ID 495, Pp no 1-8, Mexico, 1996

[15] Rana Rahul, "Response Control of Structures by Tuned Mass Dampers and their Generalizations" $11^{\text {th }}$ World Conference on Earthquake Engineering, Paper ID -498, Pp no 1-8, Mexico, 1996

[16] Shimazu Takayuki, Andaraki Hideo, "Survey of Actual Effectiveness of Mass Damper Systems Installed in Buildings" $11^{\text {th }}$ World Conference on Earthquake Engineering, Paper ID -809, Pp no 1-8, Mexico, 1996

[17] Yasui Kenji, Otsuka Susumu, Kawai Nobuyasu, Lkenaga Masayoshi, Mochimaru Masami, "Earthquake Response Observation of a Verification Tower with Active Mass Damper System" $11^{\text {th }}$ World Conference on Earthquake Engineering, Paper ID 1524, Pp no 1-8, Mexico, 1996

[18] ShimodaHirokazu, ShimosakaHaruo, Hayase Makoto, OhmataKenichiro, "Hybrid Damper for a Seismic Isolation Device for Equipments and Machines" $11^{\text {th }}$ World Conference on Earthquake Engineering, Paper ID -275, Pp no 1-8, Mexico, 1996
[19] Nakamura Yoshiya, Fujita Takafumi, Tanaka Kiyoshi, OhyamaHidemi, Murakoshi Kazuya, Miyano Hiroshi, HoraHirokazu, Sugamuna Manabu, "Development of Hybrid Mass Damper Using Linear-Induction-Servomotor for Vibration Control of Tall Buildings" $11^{\text {th }}$ World Conference on Earthquake Engineering, Paper ID -426, Pp no 1-8, Mexico, 1996

[20] Fuyama Hiroyuki, Kokubo Fiji, Fujita Katsuhisa, OgoHideyasu, Morinakalkuo,Ichihashi Ichiro, "Dampers for Heavy Components in PWR Nuclear Power Plants" $11^{\text {th }}$ World Conference on Earthquake Engineering, Paper ID -557, Pp no 1-6, Mexico, 1996

[21] Miyamoto Kit,Scholl Roger, "Case Study: Seismic Rehabilitation of a Non-Ductile Soft Story Concrete Structure Using Viscous Dampers" $11^{\text {th }}$ World Conference on Earthquake Engineering, Paper ID 315, Pp no 1-8, Mexico, 1996

[22] Watanabe Atsushi, "Some Damage Control Criteria for a Steel Building with Added Hysteresis Damper" $11^{\text {th }}$ World Conference on Earthquake Engineering, Paper ID -449, Pp no 1-6, Mexico, 1996

[23] Norio Hori, Yoko Inoue And Norio Inoue, "A Study on Energy Dissipating Behaviors and Response Prediction of RC Structures with Viscous Dampers Subjected to Earthquakes" $13^{\text {th }}$ World Conference on Earthquake Engineering, Paper ID -2, Pp no 1-11, Canada, 2004

[24] HaruhikoKurino, Yoshinori Matsunaga, Toshikazu Yamada,Jun Tagami, "High Performance Passive Hydraulic Damper with Semi-Active Characteristics" $13^{\text {th }}$ World Conference on Earthquake Engineering, Paper ID -33, Pp no 1-12, Canada, 2004

[25] Oren Lavan, Robert Levy, “Optimal Design of Supplemental Viscous Dampers for Linear Framed Structures" $13^{\text {th }}$ World Conference on Earthquake Engineering, Paper ID -42, Pp no 1-13, Canada, 2004

[26] KenichiroOmata, Toshiharu Arakawa ,YousukeMezaki, "Long Stroke Magnetic Damper for a Seismic Isolation Device for Machine" $13^{\text {th }}$ World Conference on Earthquake Engineering, Paper ID -46, Pp no 1-11, Canada, 2004

[27] Xianguo Ye, KangningLi,Xiyuan Zhou, "Analytical Evaluation of Seismic Responses of a Powerplant Frame Structure with Energy Dissipation Damper" $13^{\text {th }}$ World Conference on Earthquake Engineering, Paper ID -88, Pp no 1-10, Canada, 2004

[28] T. Y. Lee,K. Kawashima, "Effectiveness of Supplementary Dampers for Isolated Bridges Under Strong Near-Field Ground Motions" $13^{\text {th }}$ World Conference on Earthquake Engineering, Paper ID 138, Pp no 1-14, Canada, 2004

[29] Kan Shimizu, Toshikazu Yamada, Jun Tagami Haruhiko Kurino, "Vibration Tests of Actual Buildings with Semi-Active Switching Oil Damper" $13^{\text {th }}$ World Conference on Earthquake Engineering, Paper ID -153, Pp no 1-11, Canada, 2004

[30] Tomokazu Yoshioka, Masamichi Ohkubo, "Hinge Mechanism of Moment Resisting Steel Frame Using Bolted Frictional Slipping Damper" $13^{\text {th }}$ World Conference on Earthquake Engineering, Paper ID 158, Pp no 1-7, Canada, 2004 